\title{
Povoando subjetividades na "nova" política para a formação de professores no Brasil: uma discussão acerca das competências
}

\section{Populating subjectivities in the "new" politics for teacher education in Brazil: a discussion about competences}

\section{Poblando subjetividades en la "nueva" política de formación docente en Brasil: una discusión sobre competencias}

\author{
Merilin Baldan ${ }^{1}$ \\ Érika Virgílio Rodrigues da Cunha ${ }^{1}$
}

DOI: http://dx.doi.org/10.20435/serie-estudos.v0i0.1501

\begin{abstract}
Resumo: Este artigo foca na centralidade da noção de competências nos documentos normativos para a formação de professores. A aprovação da Resolução CNE/CP n. 2/2019 em substituição à Resolução CNE/CP n. 2/2015 torna relevante a investigação de como vêm sendo interpeladas as subjetividades em torno da noção de competência, normalizando o caráter cada vez mais prescrito da regulação. Objetivamos compreender de que maneira a reiteração das competências na formação de professores processa o povoamento das subjetividades. Referenciamo-nos, especialmente, em Harvey, Santos, Duarte, Ramos, Ball, Brown e Taubman. Nós nos ativemos às evocações ao neopragmatismo e à epistemologia da prática, ao longo do tempo, como sentidos que hegemonizam as competências na formação inicial de professores, explicitando como na política atual as competências produzem dois movimentos fundantes à produção de subjetividades pela razão neoliberal. Elas operam a dessacralização da educação como um valor em geral, ao mesmo tempo em que processam a sedução psíquica e a aceitação das políticas e práticas instrumentais.
\end{abstract}

Palavras-chave: política curricular; competências; formação de professores.

Abstract: The article herein focuses on the centrality of the notion of competences in normative documents for teacher education. The approval of the Resolution CNE/CP n. 2/2019 to replace Resolution CNE/CP n. 2/2015 makes relevant the investigation of how the subjectivities surrounding the notion of competence, thus normalizing the character increasingly prescribed of the regulation. Thereby, we aim to understand how the reiteration of competences in teacher education processes

\footnotetext{
${ }^{1}$ Universidade Federal de Mato Grosso, Campus Universitário de Rondonópolis, Mato Grosso, Brasil.
} 
the settlement of subjectivities. Our references were mainly Harvey, Santos, Duarte, Ramos, Ball, Brown, and Taubman. We relied on the evocation of the neopragmatism and the epistemology of practice over time as the meanings that hegemonize the competences in initial teacher education. We conclude by explaining how the competences produce two fundamental movements for the production of subjectivities for neoliberal reasons in current politics. They operate the desecration of education as a value in general, at the same time that they process psychic seduction and the acceptance of instrumental policies and practices.

Keywords: curricular policy; competences; teacher educacion.

Resumen: El presente artículo tiene como enfoque la centralidad de la noción de competencias en los documentos normativos para la formación docente. La aprobación de la Resolución CNE/ CP n. 2/2019 en sustitución de la Resolución CNE/CP n. 2/2015 hace relevante la investigación de cómo las subjetividades que rodean la noción de competencia han sido cuestionadas, normalizando pues el carácter cada vez más prescrito de la regulación. Así, buscamos comprender cómo la reiteración de competencias en la formación docente procesa el asentamiento de subjetividades. Nuestras principales referencias son Harvey, Santos, Duarte, Ramos, Ball, Brown y Taubman. Nos atenemos a las evocaciones del neopragmatismo y la epistemología de la práctica, a lo largo del tiempo, como significados que hegemonizan competencias en la formación inicial del profesorado. Concluimos explicando cómo, en la política actual, las competencias producen dos movimientos fundamentales para la producción de subjetividades por la razón neoliberal. Ellas operan la profanación de la educación como un valor en general, al mismo tiempo que procesan la seducción psíquica y la aceptación de políticas y prácticas instrumentales.

Palabras clave: política curricular; competencias; formación de profesores.

\section{INTRODUÇÃO}

A despeito de contarmos com uma longa tradição de regulamentações em torno do trabalho educativo (CIAVATTA; RAMOS, 2012), a recente homologação da Resolução CNE/CP n. 2/2019 em substituição à Resolução CNE/CP n. 2/2015 evidenciou a normatividade e o autoritarismo nas políticas atuais no Brasil. A resolução institui as Diretrizes Curriculares Nacionais para a Formação Inicial de Professores para a Educação Básica, concebidas como a Base Nacional Comum para a Formação Inicial de Professores da Educação Básica (BNC-Formação). Assim, enquanto a nova política restitui a não tão nova noção de competência disseminada amplamente pelo reformismo neoliberal dos anos de 1980 e 1990 no Ocidente, há alguns meses a pandemia de Covid-19 vem nos dando mostras de como esse modelo curricular se volta a um mercado apto a fornecer cardápios educacionais via plataformas virtuais, prometendo conectar a educação ao futuro.

O longo período que precede essa retomada exacerbada das competências, no qual tal noção ganhou centralidade nas políticas, foi marcado pelo entrelaçamento 
crescente do setor público com o privado ante as transformações do setor produtivo e gerou uma agenda educacional voltada a demandas econômicas via políticas de longo e curto prazo. A produção de uma série de normatizações, assim como a instituição do controle por meio de avaliações e indicadores estandardizados de desempenho, naturalizou a formalização das competências e o sentido prescritivo da política.

Mobilizadas por esse cenário, objetivamos compreender de que maneira a reiteração das competências na política de formação de professores processa o povoamento das subjetividades. Faremos isso, a princípio, destacando a produção de documentos que impetraram acordos e compromissos com mudanças estruturais mais objetivas. Num segundo momento, discutiremos aspectos críticos acerca das competências, destacando seu alinhamento ao ideário instrumental na política de formação de professores para, numa terceira seção, pensarmos como seu realce neoliberal, hoje, sugere mudanças mais subjetivas na formação do professor ou que alteram quem os professores devem se tornar. Investidas neoliberais imprimiram às competências a aura de uma modernização necessária à educação via uma agenda educacional global ávida por maior controle sobre os professores e, ao mesmo, voltada à desregulamentação do trabalho. Situamos, portanto, a reconfiguração da política de formação no escopo do neoliberalismo atual, cujas bases compreendem a globalização econômica intensificada no século XX a partir do estreitamento geográfico e temporal dos estados nacionais na modernidade.

A globalização deve ser entendida como um processo histórico, intermitente e irreversível de internacionalização do capital, da construção dos mercados globais, da unicidade da técnica e da produção de políticas mais eficientes (HOBSBAWM, 2009). Os discursos ideológicos da globalização operam a homogeneização, a padronização e a uniformidade das estruturas desiguais dos diferentes estados ao redor do mundo, decorrentes da distribuição e do acesso díspares da técnica e da tecnologia, da informação, dos recursos naturais e materiais e, sobretudo, da riqueza produzida (SANTOS, 2018). As preocupações se elevam quando consideramos a priorização da economia em detrimento das esferas ambientais, sociais, culturais e educacionais, principalmente nas políticas que se encaminham para totalitarismos (HOBSBAWM, 2009; SANTOS, 2018). Assim, a pobreza e a violência, desigualdades de toda ordem, agudizam os problemas estruturais da globalização e passam a ser tratadas como um problema mundial que precisa ser resolvido. 
Nesse espectro, destacam-se organismos internacionais, aos quais são concedidos poder para intervir, com os recursos financeiros dos países chamados desenvolvidos, com a anuência dos países chamados subdesenvolvidos. Eles apresentam-se como autoridades globais vinculadas à especialização, à imposição política e ao financiamento, e, sobretudo a partir dos anos de 1980, tomam decisões supranacionais por meio da apresentação de uma agenda política internacional (HOBSBAWM, 1995; 2009). Tais organismos são representados por agências multilaterais - Banco Mundial, Fundo Monetário Internacional, por exemplo.

O capitalismo, nas suas diferentes fases (liberalismo clássico, Estado de bem-estar social e neoliberalismo), vai refletir nas relações estabelecidas mundialmente, seja pela economia, seja pela divisão internacional do trabalho. Com a confluência do processo de globalização e neoliberalização, já nos anos de 1970, observou-se um desmonte do Estado do bem-estar social e a defesa do Estado mínimo na Inglaterra e no Chile, especialmente. As mudanças deste momento representaram os interesses das elites financeiras e a adaptação da sociedade às demandas do setor produtivo, induzindo a privatização do setor público, a desregulamentação do trabalho e o enfraquecimento dos sindicatos (HARVEY, 2014). Na era da neoliberalização, os empréstimos financeiros, o endividamento e a inadimplência dos países ditos subdesenvolvidos, assim como a adoção de políticas de austeridade e de ajustes, perpetuaram-se nas reformas, com maior ou menor grau de desvio dos princípios dessa ideologia. As relações entre educação, desenvolvimento e progresso, também entre trabalho e educação, passaram a ser estratégicas e ganharam força no processo de indução de políticas pelas agências multilaterais (SHIROMA; MORAES; EVANGELISTA, 2011).

Mais recentemente, Stephen J. Ball (2012) aponta o surgimento da tendência, cada vez maior, da participação dos organismos internacionais, empresas privadas, empreendedores sociais e sociedades filantrópicas na produção de agendas, configurando novas redes de governança moldadas por interesses públicos e privados. Tal tendência representa a efetiva intervenção dos interesses do capital na própria redução da capacidade de gestão dos estados nacionais. $\mathrm{Na}$ agenda educacional internacional a partir dos anos 1990, fez-se destacada a centralidade da regulamentação da formação docente, a qual passaremos a abordar, apresentando documentos e acordos produzidos no Ocidente que foram basilares àquilo que Ball (2002) chamou de tecnologias políticas para reformar 
Povoando subjetividades na "nova" política para a formação de professores no Brasil: uma discussão acerca das competências

professores e mudar o que significa ser professor. Nesse sentido, realçaremos aspectos discursivos do processo histórico que nos conecta, hoje, à "nova" política de formação de professores no Brasil.

\section{UMA AGENDA EDUCACIONAL GLOBAL}

A ampla agenda educacional internacional teve como primeiro (talvez o mais importante) documento o texto Educação: um tesouro a descobrir (UNESCO, 1996). Conhecido como Relatório Jacques Delors, o documento ensejou um diagnóstico do século XX diante do desenvolvimento técnico-científico e das desigualdades socioeconômicas e educacionais relacionadas ao desemprego e à violência, assim como projetou os desafios a serem enfrentados na educação do século XXI. O documento sinalizou para a produção de compromissos sensíveis à relação entre o global e o local, por meio de orientações internacionais e o estabelecimento de planos, diretrizes e regulamentações inclinadas à homogeneização das políticas educacionais. A agenda educacional internacional, nesse momento, incidiu, no Brasil, em reformas curriculares na educação básica e superior. No Relatório, a centralização no currículo foi justificada pela necessidade de formar identidades flexíveis, adaptáveis a um mundo realçado como em constante mudança, para o qual o investimento na massa cinzenta representaria a condição de inovação de cada país para a competitividade. Não por acaso, o Relatório costura o pressuposto da qualificação à competência e define o aprender a aprender como pilares da educação do futuro. Aprender a conhecer, aprender a fazer, aprender a ser e aprender a conviver são competências com as quais processa-se a redução do currículo aos saberes básicos, à individualização dos percursos formativos e à diversificação da formação. A inovação se impõe na linguagem restritiva da aprendizagem (de saberes básicos), ante uma escola genérica, enunciada como ultrapassada, que precisa ser urgentemente revista. O documento ainda estabelece a atenção aos condicionamentos da economia/financiamento público, sugerindo maior articulação com o setor privado e cooperações internacionais.

O Relatório Mundial da Educação: Professores e Ensino em um Mundo de Mudanças² (UNESCO, 1998) apresentou, por sua vez, exigências relacionadas às

2 Título original do documento "World education report (1998): Teachers and teaching in a changing world". 
Tecnologias de Informação e Comunicação $(T I C S)^{3}$, que repercutiriam na compreensão do papel da escola, dos professores e das políticas educacionais. O documento interpelou o compromisso dos professores com o preparo das novas gerações e realçou a necessidade de se (re)pensar políticas de formação nesse prisma. Partiu de um diagnóstico da formação inicial, continuada e em serviço, das condições de trabalho dos professores em âmbito internacional, para recomendar a adoção de padrões de desempenho, acompanhamento e avaliação das políticas implementadas, além da especialização da formação, formação continuada e accountability. Indicou, ainda, a condicionalidade dos gastos públicos à reestruturação econômica.

Eventos internacionais também foram realizados com a finalidade de se firmar acordos, legitimar e dar credibilidade às reformas, orientações, diretrizes, políticas internacionais, como o Consenso de Washington e a Conferência Mundial de Educação para Todos. Como diz Ball (2012), certas estratégias tornam críveis narrativas de "boas políticas", criam consensos globais, embora não sejam capazes de assegurar a conformidade dos discursos e das expectativas às realidades concretas dos diferentes países.

A noção de competências que marcou centralmente essas narrativas guiou, a partir da década de 1990 no Brasil, a elaboração dos Parâmetros Curriculares Nacionais e de Diretrizes Curriculares Nacionais em todos os níveis e modalidades de ensino, seguindo-se recomendações internacionais na perspectiva (também local) de priorização da economia. Reformadores que atuaram diretamente na produção desses documentos curriculares no Brasil, emblemáticos como o momento de instalação da lógica neoliberal, retornaram à cena política com a guinada à direita em 2016. São especialistas e pesquisadores que contribuíram com o texto aprovado da Base Nacional Comum Curricular (BRASIL, 2017) para a educação básica - homologada em dezembro de 2017 e amplamente reconhecida por suas semelhanças (seu assento nas competências) em relação aos PCNs dos anos 1990 - e, não obstante, atuaram na elaboração da nova política nacional de formação de professores.

3 O termo Tecnologia da Informação e Comunicação (TICS) tem sido apresentado, nos últimos anos, como Tecnologias Digitais de Informação e Comunicação (TDICs). 


\section{AS COMPETÊNCIAS E A DISPUTA PELA FORMAÇÃO DE PROFESSORES}

Vinculadas à tradição pedagógica técnica e comportamental norte-americana da segunda metade do século XX, as competências foram realçadas, sobretudo, como a marca reiterada da inovação educativa nos discursos das orientações e diretrizes internacionais e nacionais nos documentos dos anos de 1990, na educação básica, no ensino superior e, especialmente, na formação de professores. Assim, elas não são uma novidade do discurso educacional inaugurada no nosso tempo, e seu trânsito até aqui pode, certamente, estar configurando uma era - a era das competências.

Na nova política nacional de formação de professores, as competências são significadas tanto como um saber fazer quanto como um conhecimento (mensurável) a se dominar. Nas políticas do reformismo, parte das disputas para significar as competências se constituiu em demandas econômicas e políticas dos países ditos desenvolvidos, das organizações internacionais e nacionais (algumas delas mencionadas há pouco); e na reivindicação da formação para o mercado, para o trabalho remodelado pelas exigências das tecnologias. Havia também demandas por formação integral dos indivíduos, formação para a cidadania, para a sustentabilidade etc. As disputas em torno das competências na formação de professores se constituíram, portanto, hibridizadas e não sem relação com o ideário da produção flexível pós-crise de 1970, em que predominaram os modelos tayloristas e fordistas associados às políticas de bem-estar (RAMOS, 2006; CIAVATTA; RAMOS, 2012).

São essas disputas que edifica(ra)m a hegemonia das competências como organização curricular em boa parte do Ocidente, não eliminando, no entanto, outros significados atribuídos à formação (e às competências) por outros agentes não hegemônicos e contra-hegemônicos. Como construções contingentes e contextuais, os sentidos em disputa em torno das competências envolvem interpretações acerca de necessidades formativas e, não obstante, das necessidades produtivas. Dão-se na relação com as condições sócio-históricas de desenvolvimento técnico e socioeconômico do país, em que coincidem as relações sociais de produção e a integração social por meio da escola e da formação dos indivíduos, mediante a produção de um imaginário de fracassos e atrasos da escola e da formação de professores num mundo em transformação.

Ramos (2006) analisa que a noção de competências associada aos objetivos de ensino acabou por apresentar relação com as teorias comportamentalistas e 
a criação de pedagogias pautadas na aprendizagem em diferentes países. Esse movimento teve em comum a preocupação com o desempenho (performance) e a eficiência, justificada pelas novas necessidades que o setor produtivo e a ordem profissional impeliam nos novos tempos. Os pressupostos políticos, filosóficos e pedagógicos da pedagogia do aprender a aprender acomodaram a defesa das competências na formação de professores e nas políticas da educação básica, num alinhamento com ideias racionalistas, neopragmáticas, individualistas e neoliberais (ARAÚJO, 2004; DUARTE, 2003). Tendo em tela esse cenário originário, Duarte (2003), um dos críticos destacados da pedagogia do aprender a aprender, ponderou como as competências foram articuladas no bojo da tradição das ideias pedagógicas pautadas na epistemologia da prática, com sentidos de educação vinculados à Escola Nova, ao construtivismo e à defesa do professor reflexivo. $\mathrm{O}$ alinhamento às ideias racionalistas, de acordo com Araújo (2004), pode ser vislumbrado pelo domínio da objetificação, da identificação e da normatização dos conhecimentos e das operações em torno dele nas políticas curriculares e nas políticas de avaliação dos anos de 1990 em diante. Assim, sedimenta-se a perspectiva educativa de que o domínio de conhecimentos justifica a finalidade de se obter controle sobre a formação, sobre o processo de ensino-aprendizagem, sobre a avaliação dos processos pedagógicos, para um alto desempenho e a eficácia da formação. O comprometimento com o neopragmatismo se deve, para o autor, à compreensão da ausência de uma verdade baseada na leitura pós-moderna ${ }^{4}$ de que a realidade é uma construção individual dos sujeitos, de suas narrativas e de sua interpretação, levando à desconsideração dos saberes disciplinares pari passu com a desvalorização do conhecimento teórico, científico e acadêmico.

Os conhecimentos e a aprendizagem, nessa esteira, são vislumbrados por meio da sua utilidade e do seu imediatismo em relação às demandas do setor econômico e produtivo e, portanto, ganham uma função adaptativa e móvel (ARAÚJO, 2003; DUARTE, 2003). O individualismo está, igualmente, incorporado

4 Valemo-nos, aqui, do sentido histórico e filosófico de pós-modernidade como um período ou ethos (PETERS, 2000), para o qual Jean-François Lyotard compreende uma radical mudança dos valores e das práticas da modernidade, baseada na incredulidade em relação aos metarrelatos. Para o autor, as grandes narrativas são ficções a partir das quais as culturas enunciam suas crenças e práticas, suas próprias histórias como histórias unificadas, com vistas a legitimar um discurso, sedimentar a realidade, fundar uma instituição. 
Povoando subjetividades na "nova" política para a formação de professores no Brasil: uma discussão acerca das competências

a essa pedagogia por meio da individualização dos percursos formativos, assim como em relação a capacidades individuais, interesses e necessidades. A formação e o desenvolvimento das competências passam a ser objeto do indivíduo, que é, assim, responsabilizado também pela sua formação, seu sucesso e/ou fracasso profissional. É ele que tem de se tornar empregável, atualizar-se, numa revitalização da Teoria do Capital Humano ${ }^{5}$.

Para a formação de professores, tal como advogam os documentos das agências multilaterais, os princípios são reforçados pela epistemologia da prática. A esse respeito, observamos a crítica realizada às escolas e, principalmente, às universidades centradas no conhecimento e, portanto, na desvalorização dos conhecimentos teóricos, científicos e acadêmicos e na secundarização da mediação pedagógica (DIAS; LOPES, 2003; DUARTE, 2003). A defesa se pauta na aprendizagem de saberes vinculados ao cotidiano (profissional) e em competências genéricas que podem ser acessadas em conformidade com a necessidade de resolução de problemas, denotando a desvalorização da formação intelectual e política em nome de uma perspectiva adaptativa/conformativa aos conhecimentos práticos e utilitários (DIAS; LOPES, 2003; DUARTE, 2003).

Ramos (2006) pontua que foi a partir dos anos 1970 que os desenhos curriculares, justificados à formação das novas identidades sociais e profissionais de caráter provisório e adaptativo, passaram a valorizar os percursos individuais da formação e a responsabilização. A integração entre a formação e o mundo do trabalho exaltava as competências e habilidades com base nas capacidades individuais diante da diversidade de escolhas profissionais. A partir desses pressupostos, os documentos internacionais a impulsionar as políticas públicas educacionais, parâmetros e diretrizes ligaram as competências à ideologia neoliberal e suas demandas, refletindo uma perspectiva instrumental dessa noção associada a uma educação utilitária, pragmática e prática. De tal maneira, não há como vislumbrar as disputas em torno da noção de competência e a sua configuração

5 A teoria do capital humano (TCH), de acordo com Paiva (2001), difundida por Theodore Schultz (1962) entre 1940 e 1950, foi retomada nos anos 1980 e 1990. Ela se fundamenta na relação educação e desenvolvimento, por meio do investimento individual e da formação do capital social. De 1980 a 1990, com a racionalização dos recursos do sistema educacional, a educação deixa de ser pensada como contribuição ao desenvolvimento para atender a demandas do setor produtivo complexo, funções sociais de assento pragmático, asseverando o pressuposto das capacidades individuais na qualificação e na subjetividade da qualificação. 
na contemporaneidade prescindindo dos espectros neoliberal e pós-moderno. Não por acaso, as teorias psicológicas liberais e comportamentais e a primazia da ordem econômica, de reivindicação de uma nova cultura, reinscrevem-se nas políticas de formação de professores via competências com efeitos na produção das subjetividades dos professores (RAMOS, 2006; DIAS; LOPES, 2003; DUARTE, 2003), ou, como trataremos mais adiante, povoando subjetividades neoliberais.

Há tempos, Ball (2002) chama atenção para os aspectos mais objetivos da mudança educacional, que vêm sendo moldados por três elementos-chave na reforma: o mercado, a gestão e a performatividade. Não desenvolveremos essa discussão, mas é fulcral termos em tela que essas tecnologias políticas interligadas, atrativas e eficazes na tradição educacional vinculada ao Estado e ao bem-estar social desenvolveram-se combinadas (e em tensão) com tecnologias da burocracia e do profissionalismo desde 1980, no Brasil e noutros países. Elas difundiram-se numa estrutura global de gestão ao gosto das agências internacionais, sobretudo por meio dos documentos e eventos que destacamos, como também por empréstimos, programas de gestão e endividamentos. Ball (2012) também vem chamando atenção para o aparecimento de novas redes de governança, em que operam organismos internacionais, setores privados, empreendedores sociais e sociedades filantrópicas dedicadas a fazer o bem. Tais redes não apenas produzem políticas públicas, elas incidem em práticas cotidianas e novas subjetividades impelidas pela construção de uma nova cultura no âmbito da atuação do Estado. Nelas, a confluência entre agências multilaterais, eventos e governos, via práticas atuais de governança, mantém as competências como orientações centrais às políticas.

Nesse contexto amplo, a estabilidade das competências como recomendação na mudança curricular na formação de professores, no entanto, interpõe-se na precariedade das traduções políticas, realçando diferentes formas de apropriação, deslocamentos e relocalização de discursos, mesclagens e ambiguidades que afetam as expectativas em torno da política (DIAS; LOPES, 2003; BALL, 2012). Destarte, dos inúmeros efeitos dessa estabilidade nas políticas, interessa-nos, agora, discutir o povoamento das subjetividades neoliberais, uma vez que o neoliberalismo opera a descaracterização da educação como um acontecimento humano, singular, contornado por valores e por uma ética. Trata-se de buscar entender os aspectos mais subjetivos da mudança em curso ou as subjetividades das mudanças e as subjetividades em mudança, como indica Ball (2002). 


\section{A "NOVA" POLÍTICA DE FORMAÇÃO NO BRASIL E O POVOAMENTO DAS SUBJETIVIDADES}

Focaremos, aqui, as Diretrizes Nacionais para a Formação de Professores (BRASIL, 2019b), considerando aquilo que Stephen J. Ball (2011; 2012) e Wendy Brown (2019) chamam de aspectos subjetivos do neoliberalismo. Neste prisma, pontuamos que nada há de novo na "nova" política curricular da formação, aprovada pelo Conselho Nacional de Educação em 2019, que reitera o ideário pragmático e neoliberal das competências.

Ball (2012) se vincula a uma noção de neoliberalismo como um conjunto complexo, contraditório e instável de práticas dispostas por certa imaginação acerca do mercado que se estende a quase todos os aspectos de nossas vidas. Brown (2019), por sua vez, lembra-nos de que, se os debates em torno do termo neoliberalismo chegam ao extremo de contestar sua existência, eles, no entanto, não invalidam seu poder de criar mundos, como se dá com outras formações discursivas (capitalismo, socialismo, islamismo etc.). Para a autora (BROWN, 2015), é preciso pensá-lo como uma ordem normatizadora da razão, uma racionalidade posta em prática e disseminada largamente como forma de governo por, pelo menos, quatro décadas. Brown (2015) entende que a vida e/ou os próprios humanos são encarnados pelo econômico, de modo que "Toda conduta é conduta econômica; todas as esferas da existência são enquadradas e medidas por termos e métricas econômicas, mesmo quando essas esferas não são monetizadas diretamente" (p. 17). Ela também avalia como a onipresença da razão neoliberal na política e em atividades cotidianas afeta profundamente o caráter político constituinte da democracia, pondo em risco instituições, práticas democráticas liberais, assim como sonhos democráticos radicais.

Julgamos ser este o ponto de conexão fecundo à nossa discussão entre os dois teóricos, a leitura foucaultiana do neoliberalismo. O neoliberalismo captura as subjetividades ao encetar o mercado como princípio de inteligibilidade, medida e verdade da sociedade. É nesse espectro que entendemos que os futuros professores e os professores atuantes são interpelados pela nova política de formação inicial e continuada no Brasil como sujeitos a refazerem o seu trabalho e conhecimento, sua forma de atuação e conduta numa linguagem da mensuração e da técnica. Como Ball (2002) analisa, a reforma não muda apenas o que nós 
fazemos como professores, ela muda quem nós somos, nossas relações e nossa alma. Dito de outro modo, o neoliberalismo nos interpela a pensar e a agir como sujeitos do mercado, ainda que estejamos alheios a benefícios imediatos ou que não tenhamos diretamente em questão o dinheiro. Nesse sentido, ele povoa subjetividades.

O aparecimento de novas tecnologias políticas (de mercado) possibilita o cálculo do sujeito referenciado num corpo proativo, no qual a autonomia e a disciplina se autorregulam. Para Ball (2011), são transformações culturais e de valores no setor público concomitantes à formação de novas subjetividades e que têm como ponto-chave a cultura do novo gerencialismo norteada pelos discursos de excelência, efetividade e qualidade, como já realçamos, que produzem o terreno que vai "governar a razão política e a conduta dos sujeitos" (BROWN, 2019, p. 32). Ball (2011) explica ainda que, enquanto o taylorismo investiu nos sistemas de controle direto, o novo gerencialismo centra-se nas pessoas, substituindo a repressão vertical das intervenções improdutivas pela repressão do autocontrole dinamizado ante o espírito empreendedor. Como profissionais, os professores são levados (individualmente, por performances) a perseguir a excelência sempre demarcada pela busca da qualidade da educação, muitas vezes com dificuldades de contestar uma qualidade que se esquiva dos acontecimentos da vida para se orientar por estatísticas. Essa dificuldade se faz cada vez mais instalada nas políticas curriculares de formação, que contam com a sedimentação de quase quatro décadas de abstrações acerca da qualidade ou do que conta como o real na educação com base nos números.

A partir daqui, destacamos dois movimentos fundantes à interpelação dos sujeitos imbricados nessa racionalidade. O primeiro consiste no fato de que a razão neoliberal opera a dessacralização da educação como um valor em geral. A ubíqua instrumentalização na vida comercial e política também degrada a educação como um valor dos valores. Para Brown (2019), essa instrumentalização molda a cultura e a subjetividade política. A razão neoliberal exacerba o caráter pragmático da ação individual do professor como um mecanismo que desloca a educação do espaço político e incide em sua trivialização, naturalizando modelos de atuação, padrões de desempenho, conhecimentos e comportamentos defendidos como essenciais.

No campo da formação de professores, é destacada a perspectiva pragmática que embalou boa parte das pesquisas e demandas por formação nos anos 
Povoando subjetividades na "nova" política para a formação de professores no Brasil: uma discussão acerca das competências

de 1990 e 2000, como já mencionamos. Dias e Lopes (2009, p. 95) analisaram o centralismo da prática nas políticas curriculares num "antagonismo a um currículo teórico suposto como enunciado nas instituições de formação de professores: um currículo acadêmico, descontextualizado, distanciado dos processos políticos [...]". Num quadro de análise discursiva, acautelaram o risco de a teoria ser expulsa dessa interpretação pela sedimentação do acadêmico como espaço do a-político. Na política atual (BRASIL, 2019b), o centralismo na prática é reiterado via competências, apesar da já atestada ineficácia desse tipo de orientação nas políticas. Não há uma definição de competências na Resolução CNE/CP n. 2/2019 (BRASIL, 2019b), que estabelece as (novas) Diretrizes Curriculares Nacionais para a Formação Inicial de Professores para a Educação Básica e institui a Base Nacional Comum para a Formação Inicial de Professores da Educação Básica (BNCFormação). Tampouco o Parecer CNE/CP n. 22/2019 (BRASIL, 2019a), formulado com o objetivo de atualizar a Resolução CNE/CP n. 2, de 1ㅇ de julho de 2015 (BRASIL, 2015), dispõe-se a discutir a noção. Ela é tratada como dada no momento em que a Resolução CNE/CP n. 2/2019 preconiza que as aprendizagens essenciais, previstas na BNCC-Educação Básica, requerem o estabelecimento das competências profissionais dos professores. O risco de exclusão de sentidos políticos na formação de professores, tal como apontaram Dias e Lopes (2009), coloca-se pelo reducionismo dos conteúdos da formação inicial do professor aos conteúdos da educação básica. O professor competente será aquele que domina o saber a ser ensinado e o saber fazer relacionado ao ensino. A formação de professores deixa de ser o espaço-tempo da pesquisa e produção de conhecimentos em torno da educação formal, como um campo altamente complexo, sobredeterminado por questões históricas e políticas de nossa formação como país, questões econômicas e culturais, desigualdades reiteradas, para ser o espaço subserviente ao saber a ser transmitido.

A iterabilidade desses sentidos cognitivo-comportamentais realça o privilégio da epistemologia da prática (DUARTE, 2003), mas também certo sentido da docência como vocação (sacrifício e heroísmo). É o que explicitam Lopes e Borges (2015), ao discutirem como a ênfase na racionalidade prática interpela o professor (profissional) para uma reflexão permanente sobre seu fazer, com vistas a que realize, pelo ensino, a justiça social. O Art. 70 da Resolução n. 2/CNE/CP/2019, nesse sentido, define "I- compromisso com a igualdade e a equidade educacional, como 
princípios fundantes da BNCC", prescrevendo no caput "A organização curricular dos cursos destinados à Formação Inicial de Professores para a Educação Básica, em consonância com as aprendizagens prescritas na BNCC da Educação Básica" (BRASIL, 2019b). A teoria crítica curricular, por 40 anos, tem nos ensinado que igualdade e equidade não são problemas a serem resolvidos pela escola, o que se evidencia no atual contexto de desaparecimento de políticas públicas sociais que amparem a população e a ação educativa da escola no Brasil. Se desigualdade social não é o mesmo que desigualdade de conhecimentos, o projeto de conferir conhecimentos comuns a todos não é apenas impossível como é um projeto de poder calcado no pressuposto da exclusão que a ideia de conhecimentos essenciais obscurece.

Essa redução ao pragmatismo e à técnica justifica a ampliação do controle sobre a formação inicial e sobre o trabalho do professor na escola (SHIROMA; MORAES; EVANGELISTA, 2011), uma vez que "Art. 30 - Com base nos mesmos princípios das competências gerais estabelecidas pela BNCC, é requerido do licenciando o desenvolvimento das correspondentes competências gerais docentes" (BRASIL, 2019b) e que "Parágrafo único. As competências gerais docentes, bem como as competências específicas e as habilidades correspondentes a elas [...] compõem a BNC-Formação" (BRASIL, 2019b). Essa costura delirante entre esferas tão distintas, motivada por práticas e finalidades abissalmente diferenciadas e que disparará as avaliações censitárias e os processos de contratação docente precários, consiste na pavimentação necessária ao ingresso na profissão pelo notório saber. Assim, o crescente detalhamento das atividades e dos saberes peculiares ao professor não é mais que a produção de um professor genérico, que perde sua autoridade acadêmica para o controle da gestão. Por isso, se a recorrência ao termo competência opera a instrumentalização (degradação) da educação, para Lemos e Macedo (2019, p. 60), ela "aprisiona a educação a um modelo sistêmico que a descaracteriza" ao inventar um novo ser professor não mais sensível às relações e aos contextos e suas realidades complexas.

O segundo movimento fundante à interpelação dos sujeitos consiste na sedução psíquica e consequente aceitação das políticas e práticas neoliberais. Em suas pesquisas junto aos professores, Taubman (2009) analisa como na cultura da prestação de contas, peculiares ao mercado educacional, operam articulados o regime de testes, a entrada de interesses de negócios e ideologias corporativas nas micropráticas de formação de professores e escolaridade. Discursos cognitivos e 
comportamentais das ciências de aprendizado combinados ao sistema de vigilância pública e disciplina incrementam a gestão da educação conferindo-Ihe cientificidade. Por essa via, torna-se necessária a formação de um professor eficiente, responsável (accountable), empreendedor, que pode vislumbrar o sucesso de suas práticas nessa linguagem exata da auditagem. Como Ball (2012, p. 229) explica, essa racionalidade nos torna empreendedores e responsáveis, oferecendo-nos o sucesso, ao mesmo tempo em que nos torna culpados e nos transforma em "sujeitos neoliberais emaranhados nos poderes de liberdade", ante comparações, medições e constrangimentos.

No nosso caso, ao vincular a formação docente do licenciando às competências gerais na BNCC-Educação Básica (Art. 2º), a Resolução n. 2/CNE/CP/2019 (BRASIL, 2019b) encarrega o futuro professor do pleno desenvolvimento das crianças e jovens pelo ensino do conhecimento essencial. Essa hiperbolização da ideia de desenvolvimento, para além de tudo aquilo que implica um chamado dessa ordem como possibilidade de realização da vida das crianças e jovens em nosso país, também remonta a um conteúdo moral que as aprendizagens assumem na educação básica. A significação da aprendizagem como direito (de aprendizagem e desenvolvimento) - em que pese nisso a redução do direito substantivo constitucional a direito de aprender conteúdos e comportamentos - edifica o professor como o protagonista da mudança. Produz imagens de salvadores heroicos que, pelo ensino e cuidado, poderiam salvar as crianças, manter prosperando a democracia e garantir que nossos filhos fossem competitivos no mercado global (TAUBMAN, 2009). Articula-se à retórica em circulação na mídia, nas campanhas políticas, entre psicólogos, governantes etc., que produziu a interpretação de que professores incompetentes e escolas disfuncionais põem em risco o futuro das crianças e jovens, assim como da economia, da democracia e das relações raciais da nação (TAUBMAN, 2009). A solução para esse quadro sombrio é a intervenção cada vez mais orquestrada na formação, na autonomia dos professores e das escolas, submetendo-os a padrões. Os professores são posicionados ambivalentemente como profissionais responsáveis pela aprendizagem das crianças num sistema que, como nenhum outro, deixa de fora as suas vidas, porque a humanidade não encontra correspondência na indiferença da padronização.

A Resolução n. 2/CNE/CP/2019 também estabelece, pelo Artigo 4으, o engajamento profissional como a terceira competência específica da formação de 
professores, sendo as demais o conhecimento profissional e a prática profissional. Queremos pensar, ainda, nesse chamado ao engajamento na articulação com a ideia de direito de aprender já destacada. Explicitadas no § 3으 do Art. 4으 como “I - comprometer-se com o próprio desenvolvimento profissional; II- comprometer-se com a aprendizagem dos estudantes e colocar em prática o princípio de que todos são capazes de aprender", além de "III- participar do Projeto Pedagógico da escola e da construção de valores democráticos; e IV - engajar-se, profissionalmente, com as famílias e com a comunidade, visando melhorar o ambiente escolar", o engajamento necessário ao professor ocupa, principalmente, o espaço faltoso das políticas públicas sociais que os professores jamais poderão preencher. A interlocução com as famílias e a ação política dos professores na consecução de um Projeto Político-Pedagógico são, sem dúvida, importantes na ampliação da democracia na escola e na sociedade. Ocorre que o engajamento como desempenho ou comportamento hiperburocratiza o trabalho docente, reduzindo o professor ao técnico, um gestor das aprendizagens. Prescinde da ampla e sólida formação intelectual e política de capacidades como análise estrutural, crítica social, solidariedade de classe e ação coletiva, compromissada com a diferença, com a arte, com a cultura etc.

Voltando-se ao fato de que muitos docentes e formadores de professores aderem a essas políticas ${ }^{6}$, Taubman (2009) observa que fantasias de grandiosidade se fazem mescladas por sentimentos de inutilidade entre os professores, dando impulso ao compromisso de se sacrificar pelos alunos, que são tudo o que importa. A mídia e boa parte das pesquisas também conhecem (por vezes confirmam) esse tipo de fantasia que faz adoecer os professores afeitos a miragens de um horizonte inalcançável de salvação, como um dínamo de culpa, vergonha, medo e desistência da profissão. O engajamento, na gramática neoliberal, não impele o professor como um agente político, não o posiciona na luta coletiva por melhores condições de trabalho, salário e carreira, distribuição de renda e justiça social, ele se coloca como accountability, operando pari passu o enfraquecimento das associações de classe, das formas de contratação, na individualização dos rendimentos. Essa fantasia também pode ser vivida como a ilusão de que o estatuto

6 No Brasil, pesquisa realizada pela Fundação Lemann, em 2015, anunciava o apoio de 82\% dos professores da educação básica à elaboração de uma base curricular comum. 
Povoando subjetividades na "nova" política para a formação de professores no Brasil: uma discussão acerca das competências

profissional do professor finalmente se faria reconhecido nas melhores práticas, as práticas avaliáveis, o que se revela, há tempos, irrealizável.

\section{PARA FINALIZAR}

Buscamos retomar algumas das muitas problematizações sobre as competências nas políticas curriculares no Brasil, que têm assento numa vasta produção acadêmica. Seria ingênuo pensar que a crítica às competências inibiria seu realce na nova política de formação de professores num momento em que forças conservadoras ocupam o debate público mundo afora. O contexto atual é terreno propício às investidas neoliberais na educação e, por aqui, a aliança conservadores/ neoliberais só faz asseverar o desmonte de políticas sociais e de direitos, enquanto dissemina ódio, congela investimentos sociais e amplia a atuação do setor privado no Estado.

Assim, julgamos importante reconstituir brevemente o cenário de mudanças contornado pelo setor produtivo, que deflagrou novas exigências para o trabalho, e destacar a produção de documentos internacionais e nacionais em atenção a esse processo e sua culminância em uma agenda global educacional. Pinçamos aspectos do debate acadêmico sobre as competências nas políticas neoliberais ocidentais das décadas de 1980 em diante, para destacar a intensificação desse viés na aprovação autoritária da Resolução CNE/CP n. 2/2019. A nova política nacional, enunciada como BNC da Formação em substituição à Resolução CNE/ CP n. 2/2015, foi focalizada como uma retomada mais agressiva do neoliberalismo na educação, cujos efeitos não são apenas estruturais ou objetivos. Destarte, procuramos explicitar como a política nacional atua povoando subjetividades numa perspectiva de formação de professores voltada ao saber-fazer, ao domínio do conhecimento a ser ensinado e à gestão da sala de aula. Esse trato técnico e pragmático da formação se faz pela debilitação da educação como um valor dos valores, uma vez que sua complexidade é descaracterizada, sua natureza de acontecimento singular, de experiência e de relação, é negada pela padronização dos desempenhos, mesmo quando se referem a democratizar a escola, a gestão educacional, ou a valorizar a profissão.

O povoamento neoliberal das subjetividades via competências enseja um novo modo de ser professor, envolvendo tornar-se responsável (individualmente) por sua formação, atuação e desempenho. Formar o professor como um 
empreendedor é uma dinâmica que conta com sedução, adesão e culpabilização. Com tais pressupostos, a formação torna-se re-formação de relações e subjetividades, as almas dos professores são povoadas pelo encorajamento à reflexão como indivíduos que calculam sua atuação. É o que sugerem os documentos curriculares atuais, ao fazerem corresponder (numa série de tabelas) as competências gerais, as específicas e as habilidades a serem formadas nos professores.

A uniformização que as competências sugerem desconsidera nossa tradição formativa e o modo como atuamos como professores-pesquisadores no trabalho com as disciplinas teóricas e práticas nos cursos. Embora sigamos diretrizes gerais, sempre singularizamos conteúdos, atribuindo aos conhecimentos não apenas nossas perspectivas de estudo, mas nossas crenças e críticas. A unidade requerida por esse formato curricular não se sustenta diante de nossa autonomia e intelectualidade como pesquisadoras/es, que fazem seu trabalho articulado a redes de investigação com denominações teóricas e metodológicas muito plurais. Como formadores de professores, somos formados por perspectivas variadas, e isso não apenas enriquece a formação como revela que a política de formação sempre será traduzida pela história mesma da pesquisa e da formação no país em suas vertentes e embates, seus compromissos e entrelaçamentos com lutas políticas mais amplas. Assim, parece-nos que é essa pluralidade que se pretende (mas não se pode) apagar, e, nesses termos, a nova política busca uma unidade inexistente e impossível. Ela encaminha a formação à despolitização e ataca a escola e a universidade, por desconsiderar o caráter pujante da formação tal como a reivindicamos historicamente e como a conduzimos sempre na ampliação do debate sobre ela. O autoritarismo da aprovação da nova política revela a importância da atuação de nossas associações científicas e entidades de classe em torno de um projeto substantivo para a formação de professores no país, porque tecido na interlocução de nossas redes de pesquisa, fóruns e nas escolas de educação básica.

A racionalidade política que combatemos, como pesquisadoras e pesquisadores, como trabalhadoras/es da educação, não tem alçado os resultados prometidos, e as evidências desse fracasso encontram-se nas políticas das últimas décadas. Por isso, ainda que as imagens projetadas sejam sombrias, sua aprovação autoritária não decreta o fim do debate, não estanca as articulações por uma formação plural, intelectualizada, afeita às pessoas e à vida, que rejeita a linguagem da economia e que está em curso nas universidades, no ensino, na extensão e na 
Povoando subjetividades na "nova" política para a formação de professores no Brasil: uma discussão acerca das competências

pesquisa pelo país. Reivindicar sua revogação é atuar para que a racionalidade neoliberal não devore a humanidade na formação. Permaneçamos, pois, fazendo (e disputando) a formação de professores não apenas como pessoas, mas com as pessoas, como coletivo diverso e organizado, assumindo a precariedade, a negociação de sentidos, a humanidade como abertura à alteridade.

\section{REFERÊNCIAS}

ARAÚJO, Ronaldo M. de L. As referências da pedagogia das competências. Perspectiva, Florianópolis, v. 22, n. 2, jul./dez. 2004.

BALL, Stephen J. Education Inc.: new policy networks and the neo-liberal imaginary. New York: Routledge, 2012.

BALL, Stephen J. MAINARDES, Jefferson. Políticas educacionais: questões e dilemas. São Paulo: Cortez, 2011.

BALL, Stephen J. Reformar escolas/reformar professores e o terror da performatividade. Revista Portuguesa de Educação, Braga, v. 15, n. 2, p. 3-23, 2002.

BRASIL. Conselho Nacional de Educação. Conselho Pleno. Parecer n. 22/2019, de 7 de novembro de 2019. Brasília: DF, 2019a.

BRASIL. Conselho Nacional de Educação. Conselho Pleno. Resolução n. 2, de 20 de dezembro de 2019. Brasília-DF, 2019b.

BRASIL. Conselho Nacional de Educação. Conselho Pleno. Resolução n. 2, de 22 de dezembro de 2017. Brasília-DF, 2017.

BRASIL. Conselho Nacional de Educação. Conselho Pleno. Resolução n. 2, de 1o de julho de 2015. Brasília-DF, 2015.

BROWN, Wendy. Nas ruínas do neoliberalismo: a ascensão da política antidemocrática no Ocidente. São Paulo: Filosófica Politeia, 2019.

BROWN, Wendy. Undoing the demos: neoliberalism's stealth revolution near futures. New York: Zone Books, 2015.

CIAVATTA, Maria; RAMOS, Marise. A "era das diretrizes": a disputa pelo projeto de educação dos mais pobres. Revista Brasileira de Educação, Rio de Janeiro, v. 17, n. 49, jan./abr., 2012. 
DIAS, Rosanne E.; LOPES, Alice C. Sentidos da prática nas políticas de currículo para a formação de professores. Currículo sem Fronteiras, v. 9, p. 79-99, 2009.

DIAS, Rosanne E.; LOPES, Alice C. Competências na formação de professores no Brasil: o que (não) há de novo. Educação e Sociedade, Campinas, v. 24, n. 85, dez. 2003.

DUARTE, Newton. Conhecimento tácito e conhecimento escolar na formação do professor (por que Donald Schön não entendeu Luria). Educação e Sociedade, Campinas, v. 24, n. 83, ago. 2003.

HARVEY, David. O neoliberalismo: história e implicações. 5. ed. SP: Edições Loyola, 2014.

HOBSBAWM, Erik. O novo século: entrevista a Antonio Polito. SP: Companhia das Letras, 2009.

HOBSBAWM, Erik. A era dos extremos: o breve século XX (1914-1991). 2. ed. SP: Companhia das Letras, 1995.

LEMOS, Guilherme. A. R.; MACEDO, Elizabeth. A incalibrável competência socioemocional. Linhas Críticas, v. 25, p. 57-73, 2019.

LOPES, Alice C.; BORGES, Veronica. Formação docente, um projeto impossível. Cadernos de Pesquisa, São Paulo, v. 45, p. 486-507, 2015.

PAIVA, Vanilda. Sobre o conceito de "capital humano". Cadernos de Pesquisa, São Paulo, n. 113, jul. 2001.

PETERS, Michael. Pós-estruturalismo e filosofia da diferença: uma introdução. Autêntica: Belo Horizonte, 2000.

RAMOS, Marise. A pedagogia das competências: autonomia ou adaptação? 3. ed. SP: Cortez, 2006.

SANTOS, Milton. Por uma outra globalização: do pensamento único à consciência universal. 28. ed. Rio de Janeiro: Editora Record, 2018.

SHIROMA, Eneida O.; MORAES, Maria C. M. de; EVANGELISTA, Olinda. Política Educacional. 4. ed. RJ: Lamparina, 2011.

TAUBMAN, Peter M. Teaching by numbers: deconstructing the discourse of standards and accountability in education. Taylor \& Francis e-Library: New York, 2009. 
Povoando subjetividades na "nova" política para a formação de professores no Brasil: uma discussão acerca das competências

UNESCO. World education report 1998: teachers and teaching in a changing world. Paris: Unesco, 1998.

UNESCO. Educação um tesouro a descobrir: relatório para a Unesco da Comissão Internacional sobre a Educação para o Século XXI. Jacques Delors. Paris: Unesco, 1996.

\section{Sobre as autoras:}

Merilin Baldan: Doutora em Educação pela Universidade Federal de São Carlos (Ufscar). Professora adjunta do Departamento de Educação e do Programa de Pós-Graduação em Educação na Universidade Federal de Mato Grosso (UFMT), Campus Universitário de Rondonópolis. E-mail: merilinbaldan@gmail.com, Orcid: https://orcid.org/0000-0002-4605-961X

Érika Virgílio Rodrigues da Cunha: Doutora em Educação pela Universidade do Estado do Rio de Janeiro (Uerj). Professora adjunta do Departamento de Educação e do Programa de Pós-Graduação em Educação na Universidade Federal de Mato Grosso (UFMT), Campus Universitário de Rondonópolis. E-mail: erikavrcunha@gmail.com, Orcid: https://orcid.org/0000-0002-6648-5261

Recebido em: 11 de agosto de 2020 Última revisão: 18 de agosto de 2020 Aprovado em: 9 de setembro de 2020 
